\title{
Terceirização de Serviços de Tecnologia da Informação Através de Data Centers: Valor Estratégico para as Organizações Usuárias
}

Patrícia Lima Quintão ${ }^{1}$, Lidia Micaela Segre ${ }^{2}$, Bruno de Paula Ribeiro $^{3}$

${ }^{1}$ CESAMA e Faculdade Metodista Granbery - Juiz de Fora - MG - Brasil

\author{
${ }^{2}$ Universidade Estácio de Sá - Rio de Janeiro - RJ - Brasil
}

${ }^{3}$ Bull - Rio de Janeiro- RJ - Brasil

pquintaoecesama.com.br, lidiaeestacio.br, bruno.ribeiro@light.com.br

Abstract. This work aims to identify the characteristics inherent to the process of information technology outsourcing via Data Centers (DCs). To do so, we revised national and international bibliographies, analyzed qualitatively the results of a field research encompassing $18 D C s$, and undertook a case study of two corporate DC users. With reference to the contracts and services offered. we discovered that DCs users are getting increasingly more exacting to reduce costs and increase the efficiency of their business with quality, security, focus on core business and payment on demand. Furthermore, we discuss measures that should be taken into consideration when services are being contracted so as to ensure that profitable projects do not turn into business failures.

Resumo. Este artigo propõe-se a identificar as características particulares do processo de terceirização de TI através dos Data Centers (DCs), a partir de uma revisão bibliográfica nacional e internacional e de análise qualitativa dos resultados de uma pesquisa de campo em 18 DCs e de dois estudos de caso em organizações usuárias. Verificamos que os usuários de DCs estão mais exigentes em relação aos contratos e serviços oferecidos pelos DCs, para reduzir custos e aumentar a eficiência de seus negócios com qualidade, segurança, foco no core business e pagamento de serviços sob demanda. São discutidas ainda as medidas a serem consideradas na hora da contratação de serviços para não transformar projetos vantajosos em fracassos de negócio.

\section{Introducão}

O ambiente empresarial tem sido influenciado por mudanças e inovações que, a todo momento, surgem no mercado e provocam alterações de contexto. Portanto, as empresas precisam reagir rapidamente a essas transformações para garantir o seu crescimento e até mesmo a sua sobrevivência.

Uma das soluções encontradas para atingir os resultados desejados na área de TI, evitando a perda do foco no negócio principal, tem sido a entrega (de forma parcial ou integral) da responsabilidade pelo gerenciamento de ativos, recursos e/ou atividades ligadas a esta área a prestadores de serviços de DCs. 
Os DCs, no seu modelo de negócios atual, vêm disponibilizando inúmeros serviços de terceirização na área de TI, envolvendo, por exemplo, a hospedagem de dados; o gerenciamento da segurança; a manutenção de aplicativos, hardware e softwares; operações de rede e integração de sistemas (QUINTÃO, 2004).

Assim, para compreender a dinâmica do processo de terceirização de serviços de TI através dos DCs, este trabalho tem por objetivo identificar as características particulares deste novo modelo de negócios, as (des)vantagens de se utilizar um DC próprio ou de terceiros, as medidas a serem consideradas na hora de contratação destes serviços e cuidados para não transformar projetos vantajosos em fracassos de negócio.

A metodologia empregada na elaboração deste trabalho foi constituída, por un lado, de pesquisa bibliográfica nacional e internacional e, por outro, de análise qualitativa, através de entrevistas realizadas (de julho de 2003 a março de 2004) durante a pesquisa de campo em 18 DCs e de dois estudos de caso em organizações usuárias.

$\mathrm{Na}$ pesquisa bibliográfica foram coletadas informações de livros, revistas especializadas e teses. Em um segundo momento, foram realizadas entrevistas semi-estruturadas com gestores de recursos humanos e responsáveis pela área de infra-estrutura, operações e atendimento a clientes dos 18 DCs existentes no país. Por último, foram realizadas entrevistas semi-estruturadas com profissionais que ocupam cargos-chaves, ligados à gestão da terceirização, em duas organizações usuárias de serviços de DCs, cujos nomes não serão citados por compromisso de sigilo. Dentre os entrevistados cita-se: o Gerente de Infra-Estrutura, o Gerente de Tecnologia e Suporte e o Vice-Presidente de Gestão e TI. As empresas foram escolhidas por pertencer a setores que utilizam intensamente os serviços dos DCs (sendo uma do setor bancário e a outra do setor de transportes aéreos)

\section{O Ambiente de Negócios do Data Center (DC)}

Atualmente, o Brasil conta com cerca de 18 grandes DCs, divididos em quatro categorias, listadas a seguir:

- Os Data Centers Puros (ex: .comDominio) foram criados para atuarem no segmento de hospedagem, com serviços básicos, e podem obter acesso à Internet de uma multiplicidade de fornecedores de serviços de telecomunicações

- Os Operadores de Serviços de Telecomunicações (ex: MetroRED) provêem o serviço de conectividade possibilitando ao cliente uma largura de banda para acesso à rede de telecomunicações e de Internet da operadora, e com os serviços de DC criaram mais uma área de negócios para complementar a receita geral da companhia e alavancar as vendas na sua área principal - telecomunicações.

- Os Provedores Corporativos (ex: LocaWeb) ofertam pequenos serviços de hospedagem $W e b$ e tendem a concentrarem-se no desenvolvimento de conteúdo.

Os Provedores de Serviços de TI (ex: Dedalus.com, EDS, HP, IBM, OptiGlobe, SERPRO e a PRODESP) que podem oferecer desde os serviços tradicionais de TI, tais como: infra-estrutura, desenvolvimento, integração e suporte, até mesmo as soluções de TI de maior valor agregado.

No que tange ao perfil dos clientes que já utilizam a estrutura de um DC, o porte varia, desde empresas que têm um pequeno site da Internet hospedado no DC, até grandes corporações (como a Petrobrás, Natura, Sadia, Nestlé, Saraiva, Xerox), grandes serviços complementares de terceirização em TI. Dentre os utilizando-se de divicia um ambiente serviços merecem destaque. hospedagem comparth compartilhado para hospedar as aplicações do cliente que não são de missão critica); hospedagem dedicada (neste serviço a infra-estrutura é dedicada ao cliente, sendo hospedagem armazenar aplicações mais críticas); collocation (neste serviço o cliente é utilizada para armazenar aplicaçoes mais criticas), colloc Por fim, os serviços que visam o proprietário da infra-estrutura armazenada no DC). Por fim, os serviços que visam aumentar o nível de segurança e gerenciamento das aplicações do cliente, permitindo ao DC montar uma solução completa para atender às necessidades dos clientes nesta área.

\section{Data Center Próprio ou Terceirizado?}

A seguir, destacamos uma análise crítica das vantagens e/ou desvantagens de se utilizar m DC próprio ou terceirizado. Caso a organização usuária decida investir na éco a maior vantagem é a posibilidade de gestão própria das suas (1ém disso, será a própria gestora prioridades e necessidades de servicos na area de TI. Alén disso sera a propria gestora de suas atividades, o que garante uma exclusividade na definiça execução dos serviços desejados. Em contrapartida, a organização terá um alto custo para investimento e operação do DC, que exige uma complexidade crescente e profissionais investimento eperare e software. Neste capacitados a gerenciar e dar suporte à infra-estrutura de hardware e objetivo principal (QUINTÃO, 2004).

caso, a organização não irá focalizar no seu objetivo principa (QUIN

Dentre as preocupações das organizações usuárias quanto ao uso de um DC terceirizado conforme destaca Quintão (2004), pode-se citar o temor quanto segura dos processos terceirizados. No que tange segurança dos dados e dificulade de gestão dos proc lo aos benefícios da utilização de um DC merecem destaque: a otimização de custos (obtida através do compartilhamento entre os diversos clientes de links de telecomunicacões, infra-estrutura e expertise técnica); infra-estrutura confiável (tendotelenibilidade de energia elétrica se em vista que 0 DC apresenta um ambiente com disponibilidade de energia eletica, controle de umidade e temperatura, redundância nos componentes criticos e nos links de conectividade, e com segurança adequada); facilidade de atualização tecnológica (o DC comprar em escala têm acesso a tecnologias mais recentes por ter maior facilide para compar em escala e ser parceiro dos principais fabricantes de hardwaressofware (BU 2001)) e oferta de melhores serviços técnicos (pois o DC mantém uma equipe de

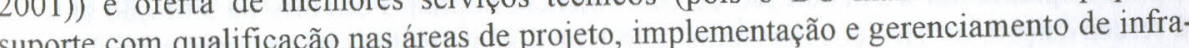
suporte com qualificação nas as incidentes ocorridos e aos chamados dos clientes, estrutura de TI, para atender os incidentes ocorridos e aos ch

fato de esses fatores serem apontados como propulsores da terceirização não ignifica que a sua efetivação traga necessariamente benefícios para as organizaçõe signírica fatores indutores do processo. Neste caso, segundo usuárias, mas apenas que são fatores indutor do pros pesquisa realizada pelo instituto The Yankee Group (ZAFFALON, 2002 empresas usuárias dos serviços de DCs no país, os principais atributos que elas levan em contratar um DC, em ordem de importância, são:

Necessidade de o DC garantir que os SLAs (Service Level Agreements), contratos que que garantem as obrigaçóes que o DC satisfação e resposta, serão cumpridos e possam ser adaptáveis às necessidades do negócio. 
- Investimentos do DC em segurança, de forma a garantir uma maior redundância de seu ambiente e aumentar a confiança dos clientes com relação a seus serviços.

Preços dos serviços devem ser competitivos, em comparação com os da concorrência. Além disso, o DC deve ter uma expertise técnica que será fundamental para garantia da qualidade dos serviços prestados.

- O prestador de serviços deve possibilitar uma agilidade no tempo necessário para provisionamento da solução do cliente, e também, deve estar acompanhando as contínuas evoluções da tecnologia disponibilizada no mercado, e propor melhorias ao cliente em caso de necessidade. Por fim, destacam-se os investimentos do DC em infra-estrutura predial e grande capacidade de conectividade; além de estar situado em um local de fácil acesso ao cliente.

De acordo com a nossa pesquisa, foram identificadas mais duas características importantes que são levadas em consideração na hora de contratar o experiência anterior do prestador de serviços deve ser comprovada (solidez); o cliente valoriza também as parcerias que o prestador de serviços tem com fornecedores líderes de mercado, para oferecimento de serviços complementares e completos. Por fim cabe ressaltar que essas variáveis podem ter a sua ordem de prioridade diferente em virtude do tipo de negócio do cliente.

\section{Estudos de Caso}

A seguir, serão apresentados os estudos de caso realizados em duas organizações usuárias, para complementar e enriquecer a análise teórica, bem como identificar algumas tendências nesta área, que serão delineadas nas conclusões deste estudo.

\subsection{Empresa Gama}

A empresa Gama é uma instituição financeira, que possui a sede na cidade do Rio de Janeiro e uma filial em São Paulo, com atuação em praticamente todo o país. Dentre os problemas que foram motivantes para a contratação dos serviços de um DC, conforme destacado pelo Gerente de Tecnologia e Suporte, cita-se: diversas interrupções de energia; ausência de equipamentos de backup para substituir os atuais em caso de falhas e para implementar a sua solução de contingência interna. Portanto, na situação anterior à terceirização, os serviços prestados pelo banco aos clientes seriam interrompidos caso alguma situação atípica acontecesse no seu ambiente de $\mathrm{TI}$, causando diversos transtornos aos clientes e perda da qualidade dos serviços prestados.

$\mathrm{O}$ banco tem como prioridade a continuidade dos serviços garantindo a satisfação do cliente, com informações confiáveis e disponíveis em tempo integral. Para tal, contratou, junto ao DC da MetroRED, em 2002, as soluções de collocation, hospedagem dedicada, links de conectividade e serviços de contingência Após a terceirização, a área de TI da empresa Gama, segundo o Gerente de Tecnologia e Suporte, pode concentrar-se mais em atividades estratégicas para o negócio do banco, podendo dispor, atualmente, de uma infra-estrutura bastante apropriada para hospedagem de seus equipamentos, além de possuir um ambiente de contingência, cujas aplicações são atualizadas periodicamente para entrar em ação em caso de desastres.

O Gerente de Tecnologia e Suporte destaca não ter tido nenhum problema no decorrer ou durante a renovação dos contratos com o prestador de serviços de $\mathrm{DC}$, e citou como inconveniente a necessidade de ter que se deslocar até a empresa MetroRED para realizar upgrades e/ou manutenção nos equipamentos hospedados no rack de collocation. No entanto, segundo destacou o Gerente tal escolha foi motivada pela redução de custos que proporcionava, tendo-se em vista que a empresa Gama ficou responsável por grande parte dos seus equipamentos instalados no DC da MetroRED. Além disso, ele minimizou o receio de perda de confidencialidade das informações críticas armazenadas nestes servidores.

\subsection{Empresa Delta}

O início das operações da empresa de transportes aéreos Delta, no país, deu-se em janeiro de 2001. Naquele momento, a empresa não possuía pessoal e uma infra-estrutura de TI apropriada para iniciar o seu negócio. Portanto, precisava de uma empresa que conseguisse implementar suas soluções de TI em um prazo de 10 a 15 dias e que oferecesse preço razoável pelo serviço.

A Delta analisou os fornecedores com referência no mercado e, por meio de consultas e estudos, contratou os serviços de um DC, em novembro de 2001, que assumiu o desafio com um bom preço, inicialmente. De acordo com o Gerente de InfraEstrutura, internamente foi concebido o que interessava, em especial as soluções tecnológicas para a empresa Delta ser mais eficiente no mercado, ganhar mais mercado e a confiança do consumidor.

A empresa utilizou os serviços deste primeiro DC por 2 anos, período em que pôde verificar o que não era eficiente em termos de relacionamento técnico, tendo-se em vista alguns problemas de disponibilidade e qualidade dos serviços deste fornecedor inicial. Dentre os problemas técnicos cita-se um episódio no qual ocorreu a indisponibilidade de 13 horas de toda a rede. Segundo o Vice-Presidente de Gestão e TI a empresa perdeu vendas e a operação dos aeroportos teve de ser feita toda manualmente. "Foi o grande stress naquele periodo de operação". Por outro lado acrescentou-se o alto custo dos serviços, que apesar de ter começado baixo, estava se tornando inviável para manutenção dos contratos junto a este prestador.

Para ajudá-la a detalhar as necessidades atuais de TI e evitar problemas futuros, a Delta especificou em um documento os serviços que desejava contratar de uma empresa terceira, com os tempos de resposta para incidentes e solução dos problemas, e o colocou no mercado com o objetivo de receber propostas de fornecedores dos serviços de $\mathrm{TI}$ requeridos.

A empresa Delta analisou as propostas recebidas, e escolheu o DC da empresa OptiGlobe por oferecer os preços mais competitivos e o que era necessário em termos de agilidade no relacionamento contratante-contratado. Dentre os serviços contratados desta empresa, merecem destaque: collocation; hospedagem dedicada; hospedagem de sites; gerenciamento da rede; suporte $24 \times 7 \times 365$; backup e restore; proteção de firewalls e detecção de intrusos. Estão hospedados hoje nesse DC cerca de 30 servidores, que armazenam bancos de dados, sistemas de manutenção de aeronaves, diversos sites da empresa, sistema de cargas (transporte de mercadorias), dentre outros.

Como os serviços de terceirização na empresa Delta vêm sendo utilizados desde o início de suas atividades, os profissionais de TI, e usuários internos não tiveram resistências junto à empresa terceira, estando bastante acostumados a interagirem neste ambiente. Na renovação de contratos, o Gerente de Infra-Estrutura destacou que a 
empresa Delta busca sempre a redução dos preços, o que pode até não ocorrer. Assim e a empresa encontrar um novo fornecedor com oferta dos elementos definidos nos SLAs em condições melhores, ela não hesita em mudar de prestador de serviços no negociação com o fornecedor atual não obtiver sucesso, apesar do desgaste e temos se a será necessário nesta mudança.

\subsection{Análise dos Resultados dos Estudos de Caso}

Quanto aos clientes de DCs, analisamos dois tipos de empresa nos estudos de caso: um do setor bancário (empresa Gama) e a outra do setor de transporte aéreo (empre Delta). A grande diferença em relação aos DCs entre as duas empresas é que a primeira mudou a área de TI contratando um DC e a segunda já nasceu utilizando-se dos serviços de terceirização de um DC. Apesar de não poder generalizar os resultados a partir de dois estudos de caso, merecem destaque os seguintes aspectos:

\section{Maior Exigência do Mercado Consumidor}

Em especial no estudo da empresa Delta, verificou-se que a organização abandonou o prestador de serviços de DC contratado inicialmente, e migrou para um concorrente. Os principais motivos apontados para esta alteração foram: a necessidade de mudança para um DC que ofereça os mesmos serviços a menores preços e descontentamento com a qualidade do atendimento e provedor inicial de hospedagem. Isso corrobora o estudo realizado, que sinaliza uma maior exigência das organizações usuárias, uma vez que, assim como os prestadores de serviços, também estão em fase de amadurecimento e aprendizado, tornando-se cada vez mais preocupadas em reduzir custos e aumentar a eficiência de seus negócios com maior qualidade.

\section{Desafios na Relação entre as Organizações Usuárias e DCs}

No primeiro estudo de caso relatado, a empresa Gama destacou o receio de perda de confidencialidade dos dados armazenados nos servidores de arquivos e de banco de dados. De acordo com a pesquisa realizada, pode-se destacar que um dos principais motivos que ainda limitam o crescimento da terceirização de serviços de DC no país está diretamente relacionado ao temor quanto à segurança (confidencialidade) dos dados. Na maior parte das vezes, os representantes de corporações ficam receosos de terem suas operações confiadas a uma única empresa, a qual também é responsável pelo gerenciamento de outros negócios. A preocupação torna-se mais relevante quando se estende para o compartilhamento de informações estratégicas da empresa -que promovem sua diferenciação e mantêm sua competitividade em relação aos seus concorrentes

No segundo estudo de caso, a empresa Delta desejava ampliar o escopo do projeto inicialmente previsto a custos menores, o que ficou inviável para a primeira empresa de DC contratada. Neste caso, cabe ressaltar que, de acordo com a pesquisa realizada, identificamos que pode haver excesso de expectativas por parte do contratante, bem como a criação de expectativas que não condizem com a realidade, deixando o prestador de serviços de DCs em situação desconfortável, na medida em que, não obstante os esforços deste último, sempre restará a sensação de que não foi obtido o que era esperado, como foi apontado também por Leite (1997). Segundo a pesquisa, é comum também o cliente aumentar o escopo do projeto e insistir em manter o orçamento contratado e prazos originais.
Tais situações, segundo Quintão (2004), têm sido resolvidas pelos fornecedores de serviços de DCs com uma definição clara de SLAs e a utilização de Gerentes de Contas, dedicados aos relacionamentos com os clientes e administração de suas expectativas junto ao DC, para que não aconteçam essas divergências. Caso isso não seja possível, o prestador de serviços deve proporcionar uma flexibilidade para alteração do escopo de serviços e contratos.

\section{Benefícios Obtidos com a Terceirização}

Para a empresa Delta, a decisão inicial para usar os serviços de um DC foi, segundo os entrevistados, econômica. O modelo de negócios da área de TI foi montado de forma a se ter uma área enxuta, leve, e com domínio do conhecimento necessário para que a empresa se diferenciasse no mercado. Tudo aquilo que a empresa tinha possibilidade de colocar em terceiros para obter mais flexibilidade, produtividade e menor custo foi externalizado.

A empresa Gama precisa contar com um ambiente de contingência que podera entrar em funcionamento em uma situação de emergência, além de dispor de uma infraestrutura de alta disponibilidade para armazenar seus servidores.

De acordo com a análise, cabe destacar que a terceirização por si só não é sinônimo de sucesso. Dependerá dos objetivos que se quer alcançar, da avaliação de custo/benefício e riscos do contrato estabelecido, do mercado, enfim, de inúmeros fatores que podem determinar o sucesso ou não dessa estratégia.

\section{Conclusões e Recomendações}

De acordo com o resultado da pesquisa, pode-se destacar que, em 2002, o mercado dos DCs sofreu sérios impactos originados pela crise econômica e pelo agravamento da desaceleração do mercado de TI, iniciado em 2001. Muitas organizações usuárias destes serviços se viram obrigadas a rever seus planos de investimento, reduzindo seus orçamentos, adiando novos projetos e paralisando aqueles que estavam em andamento e não eram tão urgentes. Os projetos imprescindíveis foram revistos, e os clientes começaram a priorizar soluções que lhes possibilitem redução de custos, melhorias operacionais e retornos mais rápidos.

A solução encontrada pelos DCs foi a passagem gradual da especificidade para a multifuncionalidade, encontrando parceiros que complementassem seus portfolios dessem uma maior abrangência na sua oferta, o que lhes permitiu atingir não somente um público-alvo maior, mas também estender a oferta para as novas demandas daqueles que já eram clientes.

Neste momento, de acordo com Quintão (2004), já se observa que os DCs, no seu modelo de negócios atual, começaram a oferecer melhores condições de aquisição de seus serviços, com preços mais baixos, prazos maiores, maior detalhamento dos SLAs e possibilidade de as empresas pagarem pelo uso real dos serviços (pagamento sob demanda).

Cabe destacar, também, que no momento da negociação dos contratos, um elemento passa a ser cada vez mais decisivo para o setor de DC: a segurança das informações. Mas, entregar o controle da informação a uma empresa terceirizada, não só é perigoso como pode ser fatal, caso o prestador de serviços não esteja comprometido em todas as etapas do processo. Um vazamento de informações para a concorrência 
uma informação errada ou até mesmo uma informação certa num momento errado podem ter resultados no mínimo catastróficos (STUTZ, 1999)

Neste caso, os DCs devem deixar transparente para as organizações usuárias sua idoneidade, bem como os diversos problemas que venha a ter no transcorrer do trabalho. A transparência é vista pelos clientes como um ingrediente fundamental para a consolidação da confiança a longo prazo, e, além disso, a organização usuária talvez possa auxiliar o DC na superação dos obstáculos, caso tenha uma visão clara do que está acontecendo (LEITE, 1997). Convém destacar também a possibilidade da organização usuária realizar auditorias periódicas no prestador de serviços de DCs, como forma de obter maior garantia da eficácia dos serviços realizados.

O momento, portanto, está bastante favorável para as organizações que estão analisando uma solução de collocation, hospedagem ou até mesmo serviços mais sofisticados, podendo envolver até a terceirização total da área de TI e telecomunicações, já que a competição nesta área esta acirrada, e os preços em queda.

Entretanto, três passos básicos devem ser observados para não transformar projetos vantajosos economicamente em grandes fracassos de negócio: o primeiro é a necessidade de abertura de uma concorrência entre diversos fornecedores e na qual a organização usuária explique em detalhes suas expectativas; no segundo, o cliente deve escolher as propostas mais adequadas aos seus negócios e realizar uma análise mais criteriosa do DC, no que tange à equipe técnica, tecnologia oferecida e até mesmo o resultado dos testes de diversas soluções; o último está na avaliação do retorno sobre investimento previsto pelo processo e que deve estar claro para as duas partes: clientes e fornecedores do serviço.

Para finalizar, a estratégia de conquista e manutenção da base de clientes dos DCs deverá estar alinhada com o desenvolvimento do seu portfolio de serviços e infraestrutura, sempre levando-se em conta que os clientes comprarão aquilo que cabe nos seus orçamentos. O diferencial deverá estar na qualidade e no valor que se poderá agregar às operações do cliente, fidelizando-os.

\section{Referências Bibliográficas}

BUSTAMANTE, J. Brazil B2B and eMarketplaces - Brazil Internet Data Center Market and Trends. IDC BR1236, v. 1, 2001.

International Data Corporation. Análise de Mercado. Brazil Internet Data Centers Market and Trends. São Paulo: IDC Brasil, \#BR1405, v. 1, 2002.

LEITE, J. C. Terceirização em Informática Sob a Ótica do Prestador de Serviços. Revista de Administração de Empresas, São Paulo, v. 37, n. 1, p.65-77, 1997.

QUINTÃo, P. L. Análise do Mercado Brasileiro de Internet Data Center com Foco nos Prestadores de Serviços: Estudos de Caso. Tese de M. Sc., COPPE/UFRJ, Rio de Janeiro, Brasil, 143 p., 2004.

STUTZ, D. Questionando a Validade do Uso da Terceirização em TI. Developers Magazine, v. 3, n. 36, pp. 26-27, ago. 1999.

ZAFFALON, F. Brazilian Data Centers: 2002 Update. The Yankee Group, 2002 